\title{
Cardioprotective Activities of Ethanolic Extract Root of Ageratum conyzoides on Alloxan-Induced Cardiotoxicity in Diabetic Rats
}

\author{
Abdulfatai Ojewale $\left(\mathbb{D},{ }^{1}\right.$ Sanusi Mada ${ }^{D},{ }^{2}$ Samson Oyebadejo ${ }^{(D)},{ }^{3}$ Adam Afodun $\left(\mathbb{D},{ }^{1}\right.$ \\ Okikioluwa Aladeyelu $\left(\mathbb{i},{ }^{4}\right.$ and Bolaji Kolawole $\mathbb{i}^{1}$ \\ ${ }^{1}$ Department of Anatomy, Faculty of Biomedical Sciences, Kampala International University, Western Campus, Bushenyi, Uganda \\ ${ }^{2}$ Department of Biochemistry, Faculty of Biomedical Sciences, Kampala International University, Western Campus, \\ Bushenyi, Uganda \\ ${ }^{3}$ Department of Medical Laboratory Sciences, Faculty of Allied Health Sciences, Kampala International University, Western Campus, \\ Bushenyi, Uganda \\ ${ }^{4}$ Department of Clinical Anatomy, Nelson Rolihlahla Mandela School of Medicine, KwaZulu-Natal University, Durban, South Africa
}

Correspondence should be addressed to Abdulfatai Ojewale; olakunle.ojewale@kiu.ac.ug

Received 2 July 2020; Revised 2 November 2020; Accepted 3 November 2020; Published 20 November 2020

Academic Editor: Kazim Husain

Copyright (c) 2020 Abdulfatai Ojewale et al. This is an open access article distributed under the Creative Commons Attribution License, which permits unrestricted use, distribution, and reproduction in any medium, provided the original work is properly cited.

\begin{abstract}
Diabetes mellitus has developed into one of the debilitating diseases disturbing the health of many people living with cardiovascular diseases in modern times. The root of Ageratum conyzoides was investigated for its effects on alloxan-induced diabetic Wistar rats' cardiac tissues. Thirty-two (32) Wistar rats weighing between 180 and $190 \mathrm{~g}$ were randomly divided into four groups. The animals in groups B-D were induced with a single dose of $150 \mathrm{mg} / \mathrm{kg}$ body weight of alloxan (ALX) intraperitoneally. They were confirmed hyperglycemic after 72 hours of induction and then sustained in hyperglycemic condition for 2 weeks. Animals in groups C and D received AC intervention, as stated above, for four weeks. The body weight of the experimental animals and blood collection for glucose estimation were taken weekly for six weeks using appropriate instruments. Biochemical assays for lipid profile, antioxidant enzymatic, and nonenzymatic markers were carried out. Histopathological changes in the cardiac tissues were also studied. Administration of $150 \mathrm{mg} / \mathrm{kg}$ of ALX to experimental rats induced diabetes and significantly reduced the body weights, significantly $(p<0.05)$ increased the glucose level, triglyceride (TG), total cholesterol (TC), and low-density lipoprotein (LDL) levels, and decreased the levels of high-density lipoprotein (HDL) and antioxidant enzymatic markers such as catalase (CAT), superoxide dismutase (SOD), and glutathione peroxidase (GPx) while the antioxidant nonenzymatic marker such as malondialdehyde (MDA) level was significantly increased. By contrast, rats given the ethanolic extract root of A. conyzoides had significantly $(p<0.05)$ increased the body weight gain, whereas the glucose levels significantly $(p<0.05)$ improved in treated diabetic rats. This extract also improved the cardiovascular system of the diabetic rats by significantly decreasing TG and LDL levels, significantly $(p<0.05)$ increasing the HDL level, significantly reducing the cardiac contents of CAT, SOD, and GPx, and significantly $(p<0.05)$ decreasing MDA. Ethanolic extract root of $A$. conyzoides exhibited antihyperglycemic and antihyperlipidemic activities and mitigates damage to the heart from the ALX-induced myocardial toxicity associated with type1 diabetes.
\end{abstract}

\section{Background}

Diabetes mellitus (DM) is a persistent metabolic disorder associated with carbohydrate, lipid, and protein metabolisms that contribute to several kinds of complications, including diabetic cardiomyopathy [1]. Diabetic cardiomyopathy is one of the significant complications of diabetes mellitus. Diabetic cardiomyopathy is the most imperative basis of death in $65 \%$ of patients with diabetes [1].

Hyperglycemia and hyperlipidemia are the most critical risk factors for cardiovascular disorders [1]. The group of lipid abnormalities was coupled with diabetes with the 
occurrence of a high concentration of triglycerides (TGs), low concentration of high-density lipoprotein (HDL), and small dense low-density lipoprotein (LDL), and plasma cholesterol levels is generally expected [2]. Persistent hyperglycemia in the course of DM contributes to diabetic complications characterized by overproduction of reactive oxygen species (ROS) and buildup of lipid peroxidation byproducts [3].

Experimental diabetes induced by alloxan (ALX) selectively disrupts the pancreas $\beta$ cells, which are known to be one of the weakest structures to oxidative stress by generating excess reactive oxygen species and produces heart lesions that are similar to human diabetic cardiomyopathy [4]. Oxidative stress contributes to increase protein, lipid, and carbohydrate metabolisms, which links with increased free radical release accompanied by a decrease in antioxidants, leading to diabetes [5]. The rate of hyperglycemia and hyperlipidemia has been extensively documented and is implicated in the pathogenesis of various cardiovascular complications, including cardiomyopathy $[1,6]$.

Nutraceutical therapies for diabetes mellitus have established growing consideration during topical times, and various antioxidants, nutritional approaches, and medicinal plants have been anticipated for the management of metabolic disorders in diabetic patients [6]. A. conyzoides belongs to the Asteraceae family. It is an annual herbaceous plant that is widely circulated tropically and commonly used in Southern Nigeria. It is a scrub with a broad crown, fissured bark, and scented white flowers [7]. The plant is commonly found in West Africa and abundant, particularly in the Southern part of Nigeria. It is located in the savannah regions and swampy areas of Nigeria. It is generally called goat weed in English, Imi Esu in Yoruba, Igwulube in Igbo, Alkama Tuturuwa in Hausa, Otiti in Efik, and Nnyano in Ibibio. The leaves and roots of $A$. conyzoides (AC) are used in India and Brazil to treat fever and gastrointestinal diseases such as diarrhea, dysentery, rheumatism, ovarian inflammation, and intestinal colic with flatulence $[8,9]$.

In Cameroon and Congo, the leaves of AC are also used traditionally to treat fever, rheumatism, headache, and colic [10, 11]. In Central Africa, it is used traditionally to treat pneumonia; it is also used as an insecticide and nematicide [12]. The leaves are also used in dressing wounds and burns, and it has been shown to exhibit antibacterial activity $[12,13]$. In reunion, the whole plant is used as an antidysenteric activity [14]. The whole plant has been used to treat colic, colds, rheumatism, spasms, and diarrhea, and it is also used as a tonic [15].

In Nigeria, the leaves and roots are useful in treating boils, leprosy, skin diseases, eye pains, and inflammation [16]. It has been shown to possess antidysenteric [17], analgesic [18], fertility, antispasmodic, and muscle relaxation properties $[19,20]$. It has also been shown to possess antiinflammatory and antipyretic properties [21]. The leaves and roots are also useful in treating hepatitis, breast myiasis sores, and arthritis $[21,22]$. It has been reported to exhibit radioprotective, cardioprotective, and hepatoprotective properties [23-25]. Phytochemical screenings have shown that $A$. conyzoides extract root contains various phytochemical constituents, including flavonoids, saponins, tannins, ter- penoids, alkaloids, and cardiac glycosides and does not contain anthracene derivatives [14, 17, 25].

Several antidiabetic plants have revealed an ameliorative effect on the cardiovascular system $[1,6]$. The leaves of $A$. conyzoides were a potential source of antidiabetic agents [26]. Despite extensive natural use of $A$. conyzoides in traditional medicine for DM and other diverse ailments, its cardioprotective effects on the persistent metabolic disorder have not been scientifically validated. Therefore, the present study was designed to investigate the cardioprotective effects of ethanolic extract root of $A$. conyzoides on cardiac damage in the metabolic disorder of ALX-induced rats.

\section{Materials and Methods}

2.1. Sources of Chemicals, Reagents, and Kits. Alloxan (ALX) was purchased from a Sigma company representative in Nigeria, Glucometer kits were also purchased from the Fine test representative in Lagos, Nigeria (Fine-test ${ }^{\circledR}$, Infopia Diagnostics). All other chemicals and reagents used in this study were of analytical grade.

2.2. Plant Material. The roots of A. conyzoides were collected from farmland in Ijebu-Ilugun, Ogun State, Nigeria, in the month of April 2016. The plant sample was identified and authenticated in the Forestry Research Institute of Nigeria (FRIN), Ibadan, Nigeria. The voucher specimen was deposited in the herbarium with a voucher number (FHI: 111925).

2.2.1. Preparation and Extraction of the Plant Material. The roots of $A$. conyzoides were washed, cut into small pieces, sun-dried at room temperature for seven days, and crushed to a coarse powder with the electric marker. The powder ( $2500 \mathrm{~g}$ ) was extracted with $96 \%$ absolute alcohol in 3 cycles using a soxhlet extractor. The crude extract was filtered with filter paper (Whatman No. 4). The filtrate was dried by a rotary vacuum evaporator at $30^{\circ} \mathrm{C}$ to obtain $387.2 \mathrm{~g}$ dry residue, a viscous brownish-coloured extract. It was stored in an airtight bottle kept in a refrigerator at $4^{\circ} \mathrm{C}$ till used. The extracted root was then reconstituted in distilled water at a suitable concentration for the experiment. Ojewale et al. [25] stated in their work that the $\mathrm{LD}_{50}$ of $A$. conyzoides was $5000 \mathrm{mg} / \mathrm{kg}$ body weight administered intraperitoneally; hence, the dosage used equivalent to $1 / 10^{\text {th }}$ dose (500 $\mathrm{mg} / \mathrm{kg}$ body weight) was selected as the highest extract dose. The dose used was consistent with the previous investigation on the plant [25].

2.3. Experimental Animals. Thirty-two (32) healthy Wistar rats weighing between 180 and $190 \mathrm{~g}$ of either sex were obtained from the Laboratory Animal Center of College of Medicine, University of Lagos, Idi-Araba, Lagos, Nigeria. The rats were housed in clean, sharp cages and kept in a spacious room under room temperature at the Animal House of Faculty of Basic Medical Sciences, Obafemi Awolowo College of Health Sciences, Olabisi Onabanjo University, Ikenne, Ogun, Nigeria.

They were fed with standard animal pellets obtained from Pfizer Feeds Plc., Nigeria, and had access to water ad libitum. They were allowed to acclimatize for 14 days to the laboratory conditions before the experiment. The principles 
governing the use of laboratory animals as laid out by the Obafemi Awolowo College of Health Sciences, Olabisi Onabanjo University Research Ethical Committee were approved with the ethical number 06-08-2017-18, and the use and care of the animals and the experimental protocol were in strict conformity with the Institute of Laboratory Animal Research (ILAR) guidelines [27].

2.4. Induction of Experimental Diabetes. ALX was prepared in fresh normal saline. Diabetes was induced by intraperitoneal (ip) injection of alloxan monohydrate $(150 \mathrm{mg} / \mathrm{kg}$ bwt $)$ in a volume of $3 \mathrm{~mL}$ [28]. After $72 \mathrm{~h}$, blood was withdrawn for blood glucose estimation monitored with a glucometer (Fine-test ${ }^{\circledR}$, Infopia Diagnostics). The animals with $\geq 250 \mathrm{mg} / \mathrm{dl}$ blood glucose levels were considered diabetic and included in the experiment [29]. The diabetic animals were randomly distributed into three groups of eight animals each while the last group, the positive control, had eight normal rats (Table 1).

2.5. Weight Variation. At the outset, the animals were weighed and then weighed every seven days from the treatment's commencement until the 42 nd day.

2.6. Determination of Fasting Blood Glucose. The diabetic rats were randomized into three (3) groups with eight (8) rats each; group B served as diabetic untreated control while groups $C$ and $D$ received graded doses of the extract by gavages and group A received normal saline once daily. The hyperglycemia was sustained and stabilized for two weeks, and the treatment was continued for four weeks. The blood samples were collected from the rat's lateral end of tail every week for six weeks and analyzed for glucose by oxidase method [30].

2.7. Animal Sacrifice. After six weeks of treatments (7 days after the experimental period), the animals were anesthetized with diethyl ether. The blood was collected through the cardiac puncture into sample bottles devoid of the anticoagulant. The samples were centrifuged at $4000 \mathrm{rpm}$ for 5 minutes to obtain the sera. The abdominal cavity of each rat was opened up through a midline abdominal incision to expose the heart. The cardiac tissue was excised and weighed; the cardiac tissue was weighed electronically and balanced. Blood was collected with a heparinized tube and was centrifuged within 10 minutes of the collection at $4000 \mathrm{rpm}$ for 5 minutes to obtain blood plasma was analyzed for lipid profile. Each animal's cardiac tissue was fixed in Bouin's fluid for 48 hours before the histological procedure commenced.

2.8. Assay of Lipid Profile. Total cholesterol (TC), total triglyceride (TG), and high-density lipoprotein-cholesterol (HDL-Chol) levels were determined by using previously modified enzymatic procedures [31]. Low-density lipoprotein-cholesterol (LDL-Chol) levels were calculated using the Friedewald equation [32].

\subsection{Evaluation of Enzymatic Antioxidants}

2.9.1. Determination of Catalase (CAT) Activity. Catalase activity was evaluated according to the method previously described by Aebi [33]. Activity of catalase was expressed as unit $\mathrm{mg}^{-1}$ protein.

2.9.2. Determination of Superoxide Dismutase (SOD) Activity. Superoxide dismutase activity was evaluated according to the method previously described by Winterbourn et al. [34]. It was expressed as $\mathrm{u} \mathrm{mg}^{-1}$ protein.

2.9.3. Determination of Glutathione Peroxidase (GPx) Activity. Glutathione peroxidase activity was determined by the method previously described by Rotruck et al. [35]. The absorbance of the product was read at $430 \mathrm{~nm}$, and it was expressed as $\mathrm{nmol}^{-1}$ protein.

\subsection{Evaluation of Nonenzymatic Antioxidant}

2.10.1. Determination of Lipid Peroxidation (Malondialdehyde). Lipid peroxidation was estimated colorimetrically by the thiobarbituric acid reactive substance (TBARS) method previously described by Buege and Aust [36]. Concentration was measured using the molar absorptive of malondialdehyde, which is $1.56 \times 105 \mathrm{M}^{-1} \mathrm{~cm}^{-1}$, and it was expressed as nmol mg ${ }^{-1}$ protein.

2.11. Histopathological Analysis. On the last day of the experiment, the cardiac tissues were removed from each group and were fixed in Bouin's fluid for 48 hours. Histopathological analysis was done as previously described by [28].

2.12. Statistical Analysis. Results were analyzed and presented as the mean \pm standard error of the mean (SEM) using GraphPad Prism 5.01. Analysis of variance (ANOVA) and Turkey's post hoc test were employed to test the significance of difference across the groups, and $p<0.05$ was considered statistically significant.

\section{Results}

3.1. Effect of Ethanolic Extract Root of A. conyzoides on Body Weight $(g)$ in ALX-Induced Diabetic Rats. The weight of animals in groups A, C, and D (Table 2) during the administration progressively increased weekly throughout the administration period. These are contrary to the animals in group B with a progressive weight loss weekly. Also, animals in group B showed a progressive weight loss (from 198.6 \pm $10.9 \mathrm{~g}$ to $162.8 \pm 10.1 \mathrm{~g}$ ); this implies that they lost weight when the animals' initial value in 1 st week and final weight of the animals in 6th week (-35.8) were compared. However, there was an increased in the weight gain of animals in the groups A, C, and D when their (1st week) initial weight $(188.4 \pm 8.6 \mathrm{~g}, 195.2 \pm 9.8 \mathrm{~g}$, and $192.2 \pm 8.8 \mathrm{~g})$ was compared with the (6th week) final weight $(212.6 \pm 10.8 \mathrm{~g}, 212.4 \pm 7.5 \mathrm{~g}$, and $221.0 \pm 8.5 \mathrm{~g})$.

3.2. Effect of Ethanolic Extract Root of A. conyzoides on Blood Glucose Level ( $\mathrm{mg} / \mathrm{dl})$ in ALX-Induced Diabetic Rats. In this present study, it was revealed that a study of the effect of the extracts on fasting blood sugar levels of diabetic rats is shown in Table 3. As indicated, the treatment of ALXinduced diabetic rats with graded doses of the root extract caused a significant $(p<0.05)$ decrease in the animals' blood 
TABLE 1: Grouping and treatments of the experimental animal.

\begin{tabular}{lr}
\hline Groups & Treatment \\
\hline A & Normal control group administered with normal saline for 6 weeks. \\
B & Diabetic untreated group was induced with $150 \mathrm{mg} / \mathrm{kg}$ bwt of alloxan and was given normal saline for 6 weeks. \\
C & Diabetic untreated rats for 2 weeks; diabetic rats were then administrated with the \\
& $250 \mathrm{mg} / \mathrm{kg}$ bodyweight of $A$. conyzoides for 4 weeks. \\
D & Diabetic untreated rats for 2 weeks; diabetic rats were then administrated with the \\
& $500 \mathrm{mg} / \mathrm{kg}$ bodyweight of $A$. conyzoides for 4 weeks.
\end{tabular}

TABLE 2: Effect of oral administration of ethanolic extract root of $A$. conyzoides for six weeks on body weight $(\mathrm{g})$ in ALX-induced diabetic rats.

\begin{tabular}{lccc}
\hline Groups & $\begin{array}{c}\text { Initial body } \\
\text { weight }(\mathrm{g})\end{array}$ & $\begin{array}{c}\text { Final body } \\
\text { weight }(\mathrm{g})\end{array}$ & $\begin{array}{c}\text { Difference in } \\
\text { body weight }(\mathrm{g})\end{array}$ \\
\hline A & $188.4 \pm 8.6$ & $212.6 \pm 10.8$ & 24.2 \\
B & $198.6 \pm 10.9$ & $162.8 \pm 10.1^{*}$ & -35.8 \\
C & $195.2 \pm 9.8$ & $212.4 \pm 7.5^{* *}$ & 17.2 \\
D & $192.2 \pm 8.8$ & $221.0 \pm 8.5^{* *}$ & 29.0 \\
\hline
\end{tabular}

Values are the meanvalues \pm standard deviation of 8 rats; group A: consisting of control rats; group B: consisting of diabetic rats; group C: consisting of treated diabetic rats received $250 \mathrm{mg} / \mathrm{kg}$ of A. conyzoides; group D: consisting of treated diabetic rats received $500 \mathrm{mg} / \mathrm{kg}$ of $A$. conyzoides. * Statistically significant when compared to the control group (A) at $p<0.05 .{ }^{* *}$ Statistically significant when compared to the diabetic untreated group (B) at $p<0.05$.

sugar concentration. At postinduction, the measurement of the blood glucose levels was on the high side. It was evident after the second week through to the last day of oral administration of $A$. conyzoides at both 250 or $500 \mathrm{mg} / \mathrm{kg}$ body weight, and the extract exhibited a significant $(p<0.05)$ reduction in blood glucose level.

3.3. Effects of the Ethanolic Extract Root of A. conyzoides on Lipid Profile Level ALX-Induced Diabetic Rats. In this study, it was observed that total cholesterol was significantly higher when rats became diabetic. In the diabetic treated groups with the ethanolic extract root of $A$. conyzoides (Table 4 ), a significant $(p<0.05)$ reduction in plasma cholesterol level was observed in experimental compared to the diabetic untreated group. The higher dose of the extract of $500 \mathrm{mg} / \mathrm{kg}(93.6 \pm 1.2$ ) exerted a more significant $(p<0.05)$ reduction compared to the $250 \mathrm{mg} / \mathrm{kg}(98.4 \pm 1.6)$. There was a gradual decrease in triglyceride levels in the $A$. conyzoides-treated groups against the diabetic untreated group. A significant $(p<0.05)$ increase was observed in diabetic treated groups' triglyceride levels compared to normal control and diabetic groups.

There was a gradual decrease in LDL levels in the A. conyzoides-treated groups as against the untreated diabetic group. A significant $(p<0.05)$ increase was observed in LDL levels in diabetic treated groups compared to the normal control group and diabetic group. There was an increase in HDL levels in all the treated groups as against the untreated. A significant $(p<0.05)$ decrease was observed in HDL levels in the diabetic untreated group compared to the normal control.
3.4. Effects of Ethanolic Extract Root of A. conyzoides on Pancreatic Antioxidant Enzymatic and Nonenzymatic Markers in ALX-Induced Diabetic Rats. In this study, it was established that diabetic untreated group (Figures 1-3) showed a statistically significant decrease $(p<0.05)$ in CAT $(10.8 \pm 0.6$ $\mathrm{u} / \mathrm{mg})$, SOD $(12.8 \pm 0.2 \mathrm{u} / \mathrm{mg})$, and GPx $(0.48 \pm 0.6 \mathrm{nmol} / \mathrm{mg})$ activities compared to normal rats without treatment. Diabetic rats treated with $A$. conyzoides significantly increased $(p<0.05)$ in cardiac CAT $(36.4 \pm 1.1$ to $38.2 \pm 1.3 \mathrm{u} / \mathrm{mg})$, SOD $(38.2 \pm 1.2$ to $40.8 \pm 1.4 \mathrm{u} / \mathrm{mg})$, and GPx $(0.96 \pm 0.5$ to $0.97 \pm 0.4 \mathrm{nmol} / \mathrm{mg}$ ) activities (Figures 1-3) compared to the diabetic untreated animals, along the same line. However, a significant decrease $(p<0.05)$ in MDA content $(4.4 \pm 0.6$ $\mathrm{nmol} / \mathrm{mg}$ ) (Figure 4) was observed in the diabetic untreated group when compared to the normal animals. Diabetic treated group with the $A$. conyzoides, however, significantly reduced the MDA $(1.48 \pm 0.2$ to $1.47 \pm 0.4 \mathrm{nmol} / \mathrm{mg}$ ) (Figure 4 ) compared to the diabetic group.

3.5. Effects of Ethanolic Extract Root of A. conyzoides on Pancreatic Antioxidant Nonenzymatic Markers in ALXInduced Diabetic Rats. It was observed that the diabetic untreated group showed a significant decrease $(p<0.05)$ in MDA content $(4.4 \pm 0.6 \mathrm{nmol} / \mathrm{mg})$ compared to the normal animals $(1.54 \pm 0.2 \mathrm{nmol} / \mathrm{mg})$. Diabetic treated group with the $A$. conyzoides, however, significantly reduced the MDA $(1.48 \pm 0.2$ to $1.47 \pm 0.4 \mathrm{nmol} / \mathrm{mg}$ ) (Figure 4 ) compared to the diabetic group.

3.6. Histopathological Findings. The photomicrograph of the normal heart (A) group showed normal myocardial and normal widening of interstitium of the heart tissue. The photomicrograph of the diabetic untreated (B) group of heart tissue revealed myocardial distortion, characterized with cellular degeneration and reduction of interstitium of the heart. The photomicrograph of the diabetic treated with $250 \mathrm{mg} / \mathrm{kg}$ of $A$. conyzoides $(\mathrm{C})$ showed that there was a slight recovery of myocardial tissue with the interstitium of the heart tissue, while the photomicrograph of the diabetic treated with $500 \mathrm{mg} / \mathrm{kg}$ of $A$. conyzoides (D) showed complete restoration of myocardial tissue following the reversal of the degenerative changes and widening the space of interstitium of the heart tissue.

\section{Discussion}

In this present study, it was revealed that blood glucose levels significantly increased. Still, body weight gain decreased after injection of ALX to the rats, contrast blood glucose, 
TABLe 3: Effect of ethanolic extract root of A. conyzoides on blood glucose level (mg/dl) in ALX-induced diabetic rats.

\begin{tabular}{lcccc}
\hline Time/groups & A & B & C & D \\
\hline 0 hour & $96.4 \pm 7.6$ & $94.8 \pm 8.4$ & $92.8 \pm 6.6$ & $88.3 \pm 4.2$ \\
72 hours & $92.2 \pm 6.9$ & $496.6 \pm 18.0$ & $489.8 \pm 15.4$ & $492.2 \pm 14.6$ \\
2 weeks & $83.7 \pm 8.6$ & $518.6 \pm 16.4$ & $504.8 \pm 12.4$ & $512.6 \pm 11.4$ \\
4 weeks & $96.8 \pm 7.4$ & $497.2 \pm 14.2$ & $246.1 \pm 11.8$ & $227.8 \pm 12.8$ \\
6 weeks & $92.4 \pm 8.4$ & $488.6 \pm 17.8$ & $149.1 \pm 14.5^{\mathrm{a}}$ & $138.4 \pm 13.4^{\mathrm{a}}$ \\
\hline
\end{tabular}

Values represent mean \pm SEM; $n=8$. Group A: consisting of control rats; group B: consisting of diabetic rats; group C: consisting of treated diabetic rats received

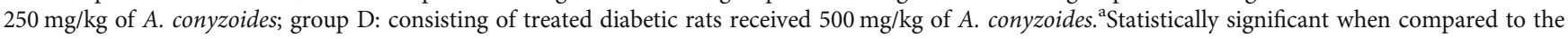
control group (A) at $p<0.05$.

TABLE 4: Effects of the ethanolic extract root of A. conyzoides on lipid profile level.

\begin{tabular}{lccccc}
\hline Group & Dose & Total cholesterol (TC) & Triglyceride (TG) & High-density lipoprotein (HDL) & Low-density lipoprotein (LDL) \\
\hline A & $92.4 \pm 2.1$ & $92.6 \pm 1.1$ & $28.4 \pm 1.1$ & $49.8 \pm 0.4$ \\
B & $321.6 \pm 8.4^{\mathrm{a}}$ & $374.7 \pm 5.7^{\mathrm{a}}$ & $14.3 \pm 0.6^{\mathrm{a}}$ & $187.4 \pm 5.2^{\mathrm{a}}$ \\
$\mathrm{C}$ & $250 \mathrm{mg} / \mathrm{kg}$ & $98.4 \pm 1.6^{\mathrm{a}, \mathrm{b}}$ & $98.9 \pm 2.4^{\mathrm{a}, \mathrm{b}}$ & $18.6 \pm 0.6^{\mathrm{a}, \mathrm{b}}$ & $61.2 \pm 2.2^{\mathrm{a}, \mathrm{b}}$ \\
$\mathrm{D}$ & $500 \mathrm{mg} / \mathrm{kg}$ & $93.6 \pm 1.2^{\mathrm{a}, \mathrm{b}}$ & $95.8 \pm 1.4^{\mathrm{a}, \mathrm{b}}$ & $26.5 \pm 0.2^{\mathrm{a}, \mathrm{b}}$ & $53.6 \pm 1.2^{\mathrm{a}, \mathrm{b}}$ \\
\hline
\end{tabular}

Values represent mean \pm SEM; $n=8$. Group A: consisting of control rats; group B: consisting of diabetic rats; group C: consisting of treated diabetic rats received $250 \mathrm{mg} / \mathrm{kg}$ of A. conyzoides; group D: consisting of treated diabetic rats received $500 \mathrm{mg} / \mathrm{kg}$ of $A$. conyzoides. ${ }^{2}$ Statistically significant when compared to the control group (A) at $p<0.05 .{ }^{\text {b }}$ Statistically significant when compared to the diabetic group (B) at $p<0.05$.

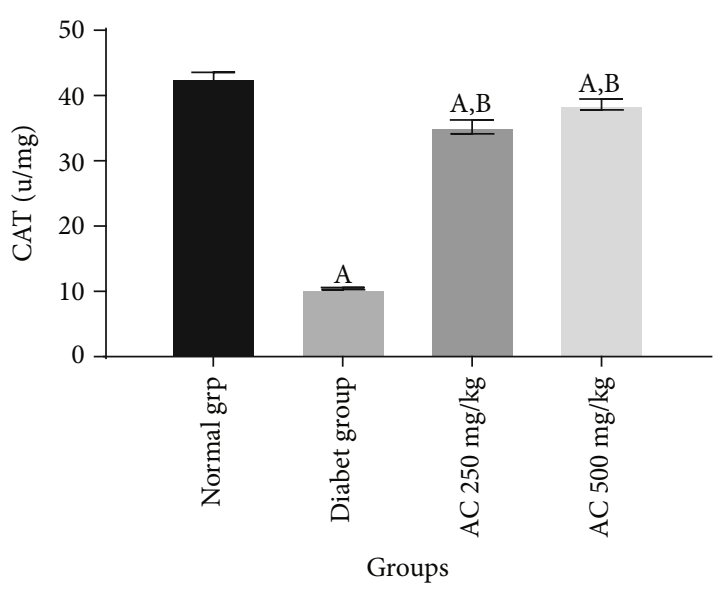

Figure 1: Effect of ethanolic extract root of A. conyzoides on cardiac enzymatic antioxidant level (CAT $\mathrm{u} / \mathrm{mg}$ ) across the groups. Values represent mean \pm SEM; $n=8$. Group A: consisting of control rats; group B: consisting of diabetic rats; group C: consisting of treated diabetic rats received $250 \mathrm{mg} / \mathrm{kg}$ of $A$. conyzoides; group D: consisting of treated diabetic rats received $500 \mathrm{mg} / \mathrm{kg}$ of $A$.

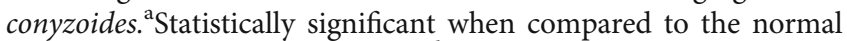
(control) group at $p<0.05$. ' ${ }^{\mathrm{b}}$ Statistically significant when compared to the diabetic untreated group at $p<0.05$.

triglyceride, total cholesterol, LDL, SOD, CAT, and GPx and had a significant decrease by distinguishing body weight; HDL and MDA had a considerable increase in diabetic rats without treatment.

Administration of $150 \mathrm{mg} \mathrm{kg}^{-1}$ of ALX to rats induced experimental diabetes and significantly reduced the body weight, which confirms the induction of diabetes compared with the diabetic treated and normal control rats. ALXinduced experimental diabetes causes a significant weight loss in body weight while treatment with $A$. conyzoides extracts significantly increases body weight. Bodyweight loss is one of the physical manifestations of diabetes that occurs due to chronic hyperglycemia, resulting in muscle wasting and loss of tissue protein and leads to increased protein glycation [37].

Oral administration of ethanolic extract root of A. conyzoides to the diabetic rats at the dose of 250 and $500 \mathrm{mg} / \mathrm{kg}$ significantly $(p<0.05)$ decreases blood glucose level in a dose-dependent manner; diabetic rats without treatment showed a numerical increase in blood glucose level compared to the normal rats. Our finding is in accordance with the reports of $[25,26]$.

Ethanolic extract root of A. conyzoides has been shown to possess the following phytochemical constituents: tannins, reducing sugars, saponins, alkaloids, terpenoids, flavonoids, steroid glycosides, and carbohydrate. Flavonoids, saponins, and terpenoids have been implicated to have known to be bioactive substances against diabetes $[25,39]$.

The significant reduction of glucose concentration could partly be that the phytochemical constituents of A. conyzoides promoted glucose entry into cells to reduce the release of glucose in the blood. This study showed that ALX-induced diabetes led to various lipid abnormalities, and it has been reported in previous studies that the activities of ALX caused lipid profile derangement $[30,38,39]$. The marked increase in the high concentration of serum lipids was mainly due to the activation of the hormone-sensitive lipase during insulin insufficiency, which may be due to the rise in the release of fatty acids from peripheral tissue to the blood vessels. 


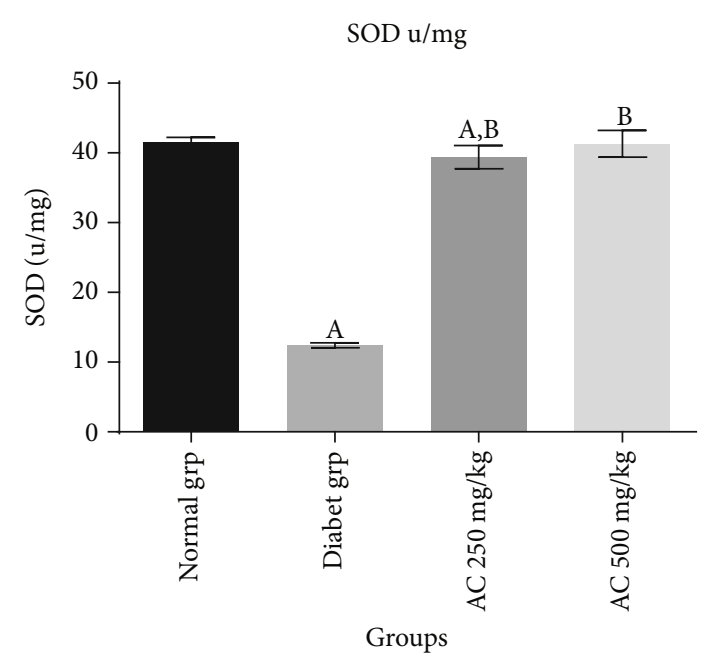

Figure 2: Effect of ethanolic extract root of $A$. conyzoides on cardiac enzymatic antioxidant level (SOD $\mathrm{u} / \mathrm{mg}$ ) across the groups. Values represent mean \pm SEM; $n=8$. Group A: consisting of control rats; group B: consisting of diabetic rats; group C: consisting of treated diabetic rats received $250 \mathrm{mg} / \mathrm{kg}$ of $A$. conyzoides; group D: consisting of treated diabetic rats received $500 \mathrm{mg} / \mathrm{kg}$ of $A$. conyzoides. ${ }^{\text {a }}$ Statistically significant when compared to the normal (control) group at $p<0.05$. 'btatistically significant when compared to the diabetic untreated group at $p<0.05$.

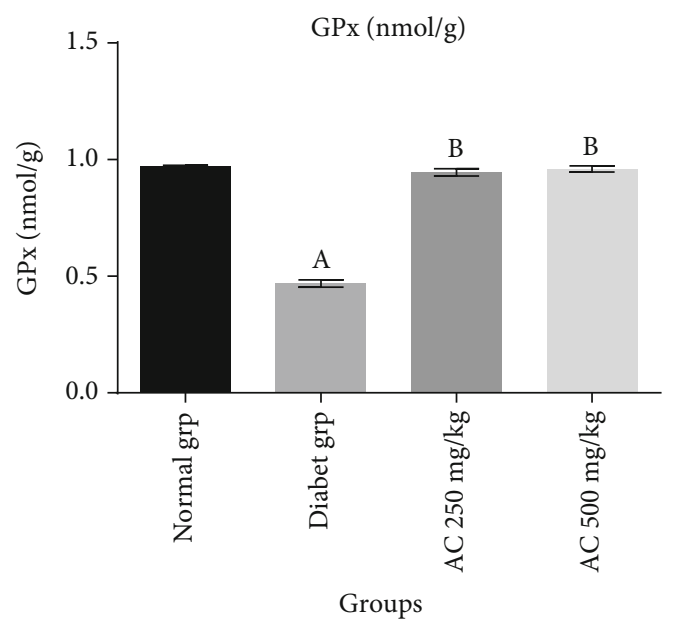

FIGURE 3: Effect of ethanolic extract root of $A$. conyzoides on cardiac enzymatic antioxidant level (GPx nmol/g) across the groups. Values represent mean \pm SEM; $n=8$. Group A: consisting of control rats; group B: consisting of diabetic rats; group C: consisting of treated diabetic rats received $250 \mathrm{mg} / \mathrm{kg}$ of $A$. conyzoides; group D: consisting of treated diabetic rats received $500 \mathrm{mg} / \mathrm{kg}$ of $A$.

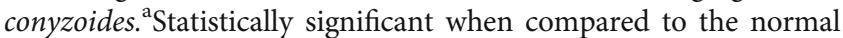
(control) group at $p<0.05$. ' Statistically significant when compared to the diabetic untreated group at $p<0.05$.

Diabetes is a debilitating disease associated with hyperglycemia characterized by dyslipidemia, which is a risk factor for coronary heart diseases [40].

When the experimental rats became hyperglycemic in lipid studies, there was an elevated level of total cholesterol, which was implicated along with the marked increase of triglyceride, which activates the enzyme lipoprotein lipase, an

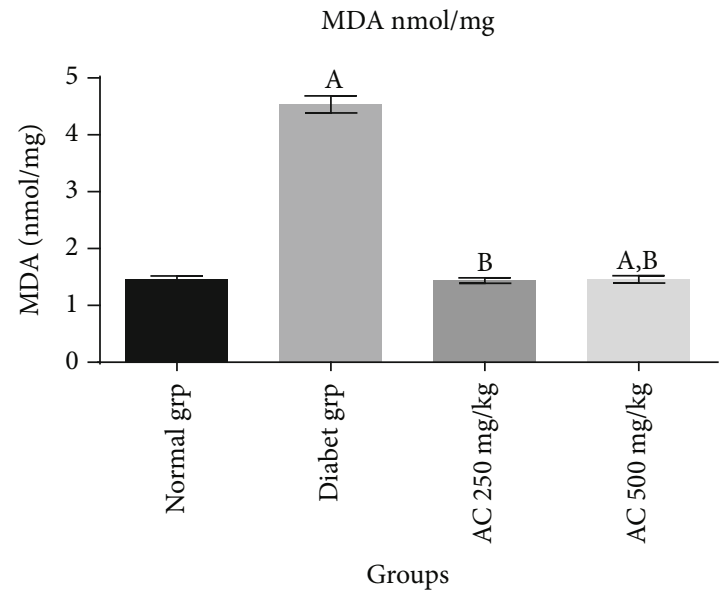

FIgURE 4: Effect of ethanolic extract root of A. conyzoides on cardiac nonenzymatic antioxidant level (MDA nmol/mg) across the groups. Values represent mean \pm SEM; $n=8$. Group A: consisting of control rats; group B: consisting of diabetic rats; group C: consisting of treated diabetic rats received $250 \mathrm{mg} / \mathrm{kg}$ of $A$. conyzoides; group D: consisting of treated diabetic rats received $500 \mathrm{mg} / \mathrm{kg}$ of $A$.

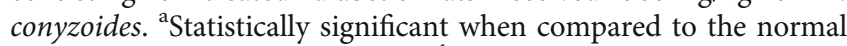
(control) group at $p<0.05$. ' Statistically significant when compared to the diabetic untreated group at $p<0.05$.

atherogenic pattern of risk factors that include a lower level of HDL-cholesterol. Higher LDL concentrations are predictive of coronary events independent of other coronary disease risk factors [41, 42, 43]. Several antidiabetic plants have been implicated in mitigating blood plasma lipid levels, usually curtailing the risk of exposure to cardiovascular disease [43-45]. This study established the efficacy of A. conyzoides root extract ameliorating hyperlipidemia. The subdued extract activation of the hormone-sensitive lipase during insulin insufficiency may be due to the rise in the release of fatty acids from peripheral tissue to the blood vessels. Our finding is in arrangement with the reports of Ahmed et al. [45], Mbaka et al. [46], and Udenze et al. [47].

It has been reported that the cytotoxic action of ALX is mediated by the formation of free radicals such as superoxide and catalase radicals, which selectively damages the $\beta$ cells of the pancreas, which are known to be one of the weakest structures to oxidative stress by generating excess reactive oxygen species and produces heart lesions that are similar to human diabetic cardiomyopathy $[4,6]$.

Excessive ROS production that exceeds critical levels can overcome all the heart's antioxidants' protection strategy, causing oxidative stress that damages the biological tissues in the hearts. This, in turn, may cause the degeneration of the myocardium, which distorts myocardial and reduces the interstitium space of the heart (Figure 5(b)) [4]. However, the extract suppresses ALX's cytotoxic action by causing the regeneration of the myocardium, which restores myocardial tissues and increases the heart's interstitium space, which was observed in the histoarchitectural analysis (Figure 5(c) and Figure 5(d)). Appraisal of SOD, CAT, GPx, lipid peroxidation, and other antioxidant enzyme activities in biologicaltissue has always been used as markers for oxidative stress [48, 49]. 


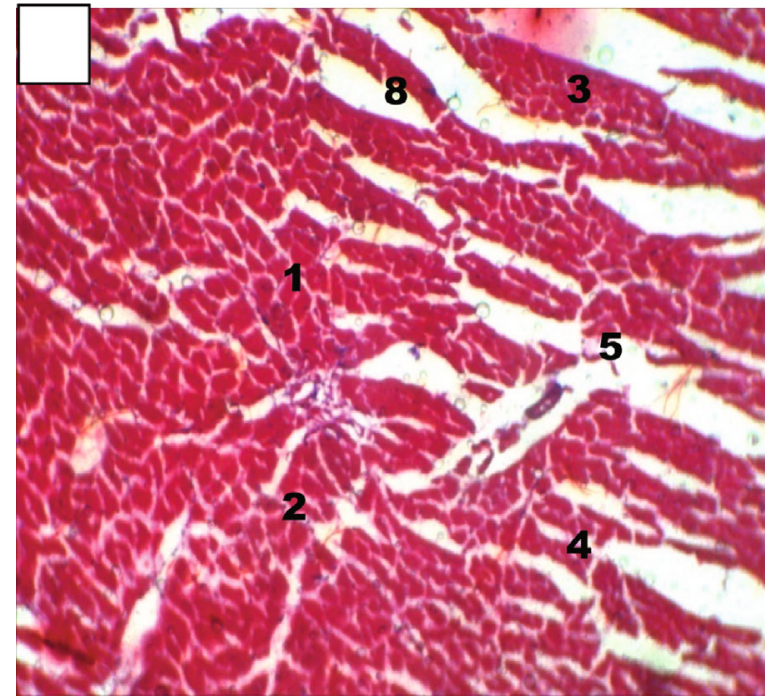

(a)

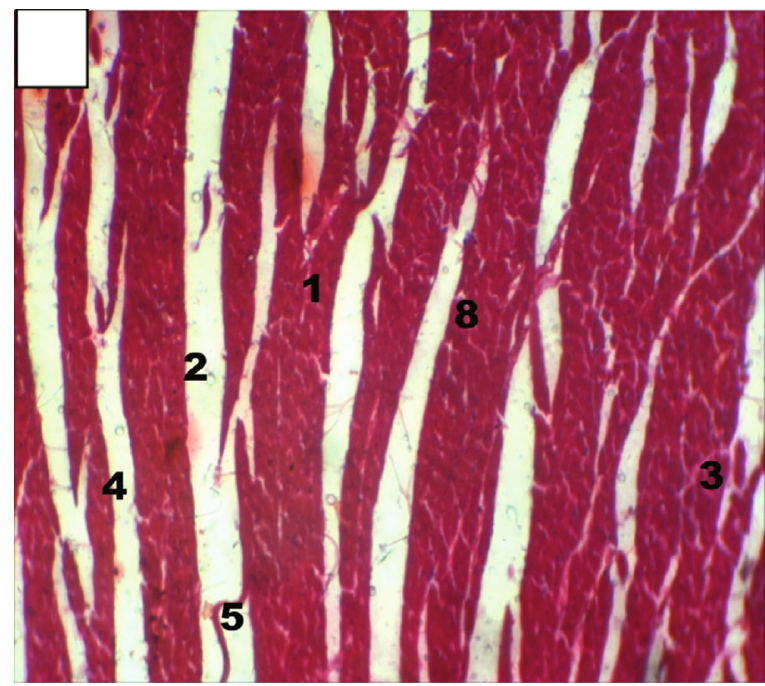

(c)

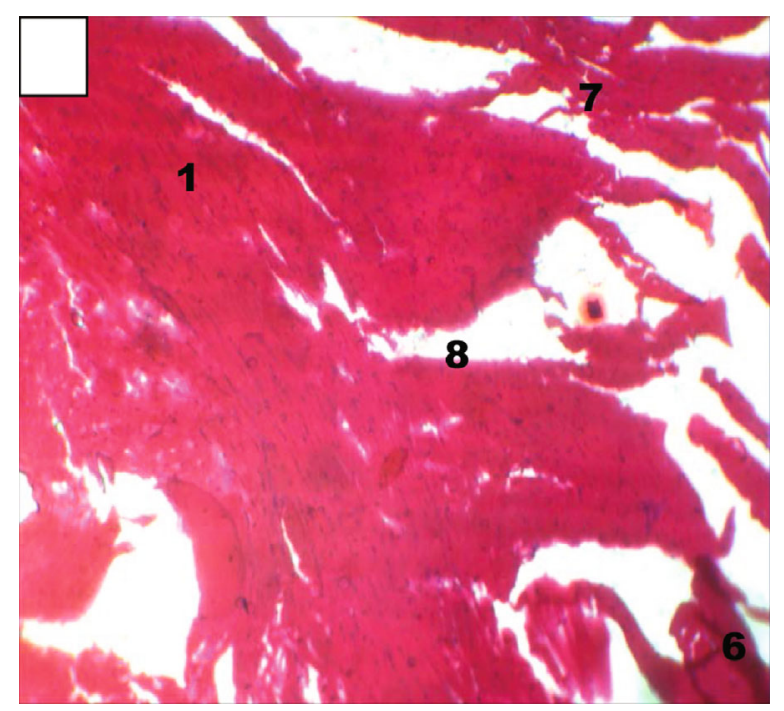

(b)

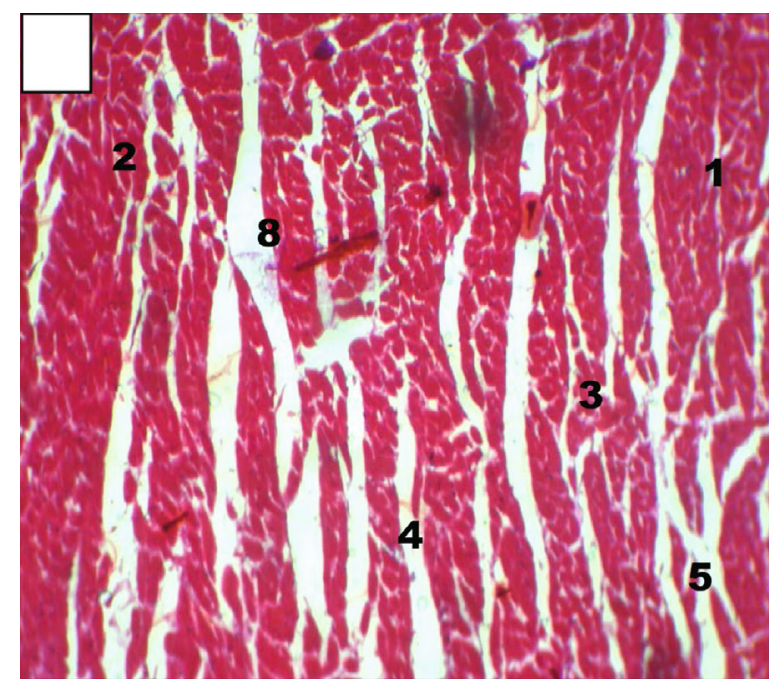

(d)

FIGURE 5: (a-d) The photomicrograph of the heart tissue in (a) normal control, (b) diabetic untreated, (c) diabetic treated with $250 \mathrm{mg} / \mathrm{kg}$ of A. conyzoides, and (d) diabetic treated with $500 \mathrm{mg} / \mathrm{kg}$ of A. conyzoides rats. Magnification $\times 100$, stained with $\mathrm{H} \& \mathrm{E}$. 1 : cardiac muscle cells; 2 : cardiac muscle nuclei; 3: intercalated discs; 4: striations; 5: myofibrils; 6: cellular degeneration; 7: myocardial distortion; 8: interstitium.

In this study, diabetic rats treated with the A. conyzoides markedly alleviate the oxidative damage by ALX induced in rats. It was observed that the administration of A. conyzoides upturned the enhanced lipid peroxidation and the consequent decline in the level of enzymatic antioxidant (GPx, SOD, and CAT) as well as the activities of nonenzymatic antioxidant (MDA) in the cardiac tissue of diabetic rats. Our finding is in accordance with the reports of $[6,28,49,50]$.

This study suggests that $A$. conyzoides does not have cardiotoxic effects. Still, relatively, it could potentially be further investigated for use in the management of the development of diabetes and improved the structure and functions of the heart.

\section{Conclusion}

Oral administration of ethanolic extract root of A. conyzoides exhibited antihyperglycemic and antihyperlipidemic activi- ties and mitigates damage to the heart from the cardiac toxicity with ALX-induced diabetes. It could be used as an antidiabetic agent with a potent cardioprotective effect, and this effect may be attributed to a variety of phytochemical constituents present in A. conyzoides.

\section{Data Availability}

The datasets generated during the analysis used to support our findings of this study are available from the first and corresponding authors on reasonable requests.

\section{Disclosure}

Authors funded this research work, and they played roles in the design of the study, data collection, data analysis, and interpretation of histology. 


\section{Conflicts of Interest}

The authors have no conflicts of interest to declare.

\section{Authors' Contributions}

This work was carried out in collaboration between all authors. Author AO designed the study and performed the statistical analysis. He equally wrote the first draft of the manuscript and undertook the final editing of the paper. Author SM wrote the protocol, part of the draft, and embarked in the paper's initial editing. Authors AA and OA carried out most of the literature searches while author $\mathrm{BK}$ handled the tissue processing for histology, and author SO performed the histological analysis. All authors read and approved the final manuscript.

\section{References}

[1] S. S. Patel and R. K. Goyal, "Prevention of diabetes-induced myocardial dysfunction in rats using the juice of the Emblica officinalis fruit," Experimental \& Clinical Cardiology, vol. 16, no. 3, pp. 87-91, 2011.

[2] R. Bitzur, H. Cohen, Y. Kamari, A. Shaish, and D. Harats, "Triglycerides and HDL cholesterol: stars or second leads in diabetes?," Diabetes Care, vol. 32, Supplement 2, pp. S373-S377, 2009.

[3] J. Yachamaneni and S. Dhanraj, "Anti-hepatotoxic and antioxidant activity of Limnanthemum indicum against carbon tetrachloride induced liver toxicity in rats," Indian Journal of Pharmaceutical Education and Research, vol. 51, no. 2, pp. 321-328, 2017.

[4] R. P. Robertson, J. Harmon, P. O. T. Tran, and V. Poitout, “ $\beta$ Cell glucose toxicity, lipotoxicity, and chronic oxidative stress in type 2 diabetes," Diabetes, vol. 53, Supplement 1, pp. S119-S124, 2004.

[5] A. K. Mohamed, A. Bierhaus, S. Schiekofer, H. Tritschler, R. Ziegler, and P. P. Nawroth, "The role of oxidative stress and NF- $\kappa \mathrm{B}$ activation in late diabetic complications," BioFactors, vol. 10, no. 2-3, pp. 157-167, 1999.

[6] R. K. Goyal and S. S. Patel, "Cardioprotective effects of gallic acid in diabetes-induced myocardial dysfunction in rats," Pharmacognosy Research, vol. 3, no. 4, pp. 239-245, 2011.

[7] G. C. Cruz, Dictionary of Useful Plants in Brazil, Zedo Civilizacao Brasileria, Bertrand Brasil, Rio de Janerio, Brazil, 1985.

[8] D. Acharya, Medicinal Plants in Urban Area of Chihindwara Town: A Survey Based Report, Jabalpur, India, 2008.

[9] M. de Fátima Agra, P. F. de Freitas, and J. M. Barbosa-Filho, "Synopsis of the plants known as medicinal and poisonous in Northeast of Brazil," Revista Brasileira de Farmacognosia, vol. 17, no. 1, pp. 114-140, 2007.

[10] C. Menut, G. Lamaty, P. H. A. Zollo, J. R. Kuiate, and J. M. Bessière, "Aromatic plants of tropical central Africa. Part X chemical composition of the essential oils of Ageratum houstonianum Mill. and Ageratum conyzoides L. from Cameroon," Flavour and Fragrance Journal, vol. 8, no. 1, pp. 1-4, 1993.

[11] D. Bioka, F. F. Banyikwa, and M. A. Choudhuri, "Analgesic effects of a crude extract of Ageratum conyzoides in the rat," Acta Horticulturae, vol. 332, pp. 171-176, 1993.
[12] J. Durodola, "Antibacterial property of crude extracts from A herbal wound healing remedy - Ageratum conyzoides, L.," Planta Medica, vol. 32, no. 8, pp. 388-390, 1977.

[13] M. Anisuzzaman, H. M. M. Rahman, M. Harunor-Rashid, A. T. M. Naderuzzaman, and A. K. M. R. Islam, "An ethnobotanical study of Madhupur, Tangail," Journal of Applied Sciences Research, vol. 3, no. 7, pp. 519-530, 2007.

[14] R. Vera, "Chemical composition of the essential oil of Ageratum conyzoides L. (Asteraceae) from Réunion," Flavour and Fragrance Journal, vol. 8, no. 5, pp. 257-260, 1993.

[15] F. Oliveria, M. K. Akisue, and L. O. Garcia, "Caracterizacao farmacognostica da droga e do extrato fluido de mentrasto, Ageratum conyzoides L," Lecta, Bragança Paulista, vol. 11, no. 1, pp. 63-100, 1993.

[16] T. Odugbemi, Medicinal Plant by Species Names: Outlines and Pictures of Medicinal Plants from Nigeria, Lagos University Press, 2006.

[17] O. Ekundayo, I. Laakso, and R. Hiltunen, "Essential oil of Ageratum conyzoides," Planta Medica, vol. 54, no. 1, pp. 5557, 1988.

[18] A. A. Abena, G. S. Kintsangoula Mbaya, J. M. Olantama, and D. Bioka, "Analgesic effects of a raw extract of Ageratum conyzoides in the rat," L'encephale, vol. 19, no. 4, pp. 329-332, 1993.

[19] K. J. Achola and R. W. Munenge, "Bronchodilating and uterine activities of Ageratum conyzoides extract," Pharmaceutical Biology, vol. 36, no. 2, pp. 93-96, 2004.

[20] M. J. M. e Silva, F. R. Capaz, and M. R. Vale, "Effects of the water soluble fraction from leaves ofAgeratum conyzoides on smooth muscle," Phytotherapy Research, vol. 14, no. 2, pp. 130-132, 2000.

[21] O. K. Ogbalu and J. O. Williams, "The use of Ageratum conyzoides L. [Asteraceae] as a therapeutic measure in the treatment of breast myiasis sores in rural women and associated bacteria," IOSR Journal of Pharmacy and Biological Sciences, vol. 9, no. 6, pp. 44-50, 2014.

[22] S. O. Ita, E. O. Akpanyung, B. I. Umoh, E. E. Ben, and S. O. Ukafia, "Acetaminophen induced hepatic toxicity: protective role of Ageratum conyzoides," Pakistan Journal of Nutrition, vol. 8, no. 7, pp. 928-932, 2009.

[23] J. K. Achola, R. W. Munenge, and A. M. Mwaura, "Pharmacological properties of root and aerial parts extracts of Ageratum conyzoides on isolated ileum and heart," Fitoterapia, vol. 65, pp. 322-325, 1994.

[24] G. C. Jagetia, A. Shirwaikar, S. K. Rao, and P. M. Bhilegaonkar, "Evaluation of the radioprotective effect of Ageratum conyzoides Linn extract in mice exposed to different doses of gamma radiation," The Journal of Pharmacy and Pharmacology, vol. 55, no. 8, pp. 1151-1158, 2003.

[25] A. O. Ojewale, H. B. Akpan, F. A. Faduyile, P. D. Shallie, A. A. Akande, and A. K. Adefule, "Hepatoprotective activities of ethanolic roots extract of Ageratum conyzoides on alloxaninduced hepatic damage in diabetic Wistar rats," Journal of Morphological Sciences, vol. 36, no. 1, pp. 039-045, 2019.

[26] N. Ngunaï, N. Nijikan, E. H. Abdennali, J. T. Mbafor, and D. Lamnaouer, "Blood glucose lowering effect of hypoglycaemic and antihyperglycaemic activity of Ageratum conyzoides $\mathrm{L}$ in rats," African Journal of Traditional, Complementary and Alternative Medicines, vol. 6, no. 2, pp. 123-130, 2009.

[27] ILAR (Institute of Laboratory Animal Research), Commission on Life Science, National Research Council, 1996. 
[28] A. O. Ojewale, A. O. Adekoya, F. A. Faduyile, O. K. Yemitan, and A. O. Odukanmi, "Nephroprotective activities of ethanolic roots extract of Pseudocedrela kotschyi against oxidative stress and nephrotoxicity in alloxan-induced diabetic albino rats," British Journal of Pharmacology and Toxicology, vol. 5, no. 1, pp. 26-34, 2014.

[29] S. Lenzen, "The mechanisms of alloxan and streptozotocininduced diabetes," Diabetologia, vol. 51, no. 2, pp. 216-226, 2008.

[30] G. O. Mbaka, S. O. Ogbonnia, and A. E. Banjo, "Activity of Raphia hookeri root extract on blood glucose, lipid profile and glycosylated haemoglobin on alloxan induced diabetic rats," Journal of Morphological Sciences, vol. 29, no. 3, pp. 19, 2012.

[31] K. M. Wasan, S. Najafi, J. Wong, and M. Kwong, "Assessing plasma lipid levels, body weight, and hepatic and renal toxicity following chronic oral administration of a water soluble phytostanol compound FM-VP4, to gerbils," Journal of Pharmaceutical Sciences, vol. 4, no. 3, pp. 228-234, 2001.

[32] M. A. Crook, Clinical Chemistry and Metabolic Medicine, Hodder Arnold, London, UK, 7th edition, 2006.

[33] H. Aebi, "Catalase," in In Methods of Enzymatic Analysis, H. Bergmeyer, Ed., p. 273, Verlag Chemical, Weinheim, Germany, 1984.

[34] C. C. Winterbourn, R. E. Hawkins, M. Brian, and R. W. Carrell, "The estimation of red cell superoxide dismutase activity," The Journal of Laboratory and Clinical Medicine, vol. 85, no. 2, pp. 337-341, 1975.

[35] J. T. Rotruck, A. L. Pope, H. E. Ganther, A. B. Swanson, D. G. Hafeman, and W. G. Hoekstra, "Selenium: biochemical role as a component of glutathione peroxidase," Science, vol. 179, no. 4073 , pp. 588-590, 1973.

[36] J. A. Buege and S. D. Aust, "Microsomal Lipid Peroxidation," in Methods of Enzymology, S. Fleischer and L. Packer, Eds., pp. 302-310, Academic Press, New York, NY, USA, 1978.

[37] G. Mbaka, A. Ojewale, S. Ogbonnia, and D. Ota, “Antihyperglycaemic and antihyperlipidaemic activities of aqueous ethanol root extract of Pseudocedrela kotschyi on alloxan-induced diabetic rats," British Journal of Medicine and Medical Research, vol. 4, no. 36, pp. 5839-5852, 2014.

[38] T. C. Odom, E. A. Udensi, and C. A. Ogbuji, "Evaluation of hypoglycemic properties of mucuna cochichinensis unripe carica papaya and unripe musa paradisiaca flour blends," European Journal of Biology and Medical Science Research, vol. 1, no. 1, pp. 15-22, 2013.

[39] R. R. Chattopadhyay and M. Bandyopadhyay, "Effect of Azadirachta indica leaf extract on serum lipid profile changes in normal and streptozotocin induced diabetic rats," African Journal of Biomedical Research, vol. 8, no. 2, pp. 101-104, 2006.

[40] V. H. Bhaskar and S. A. Sumant, "Antihyperglycemic and antihyperlipidemic activities of root extracts of Calotropis procera (Ait.) R.Br on streptozotocin induced diabetic rats," Jordan Journal of Biological Sciences., vol. 2, no. 4, pp. 177-180, 2009.

[41] B. Murali, U. M. Upadhyaya, and R. K. Goyal, "Effect of chronic treatment with Enicostemma littorale in noninsulin-dependent diabetic (NIDDM) rats," Journal of Ethnopharmacology, vol. 81, no. 2, pp. 199-204, 2002.

[42] G. J. Blake, J. D. Otvos, N. Rifai, and P. M. Ridker, "Low-density lipoprotein particle concentration and size as determined by nuclear magnetic resonance spectroscopy as predictors of cardiovascular disease in women," Circulation, vol. 106, no. 15, pp. 1930-1937, 2002.

[43] E. D. Eze, A. Mohammed, K. Y. Musa, Y. Tanko, and A. S. Isa, "Effect of ethanol leaf extract of Muncuna pruriens (Fabaceae) on lipid profile in alloxan-induced diabetic Wistar rats," British Journal of Pharmacology and Toxicology, vol. 3, no. 3, pp. 102-109, 2012.

[44] C. E. N. Momo, J. E. Oben, D. Tazoo, and E. Dongo, "Antidiabetic and hypolipidemic effects of Laportea ovalifolia (Urticaceae) in alloxan induced diabetic rats," African Journal of Traditional, Complementary and Alternative Medicines, vol. 3, no. 1, pp. 36-43, 2005.

[45] O. M. Ahmed, A. A. Moneim, I. A. Yazid, and A. M. Mahmoud, "Antihyperglycemic, antihyperlipidemic and antioxidant effects and the probable mechanisms of action of Ruta graveolens infusion and Rutin in nicotinamidestreptozotocin-induced diabetic rats," Diabetologa Croatica, vol. 39, pp. 15-35, 2010.

[46] G. O. Mbaka, S. O. Ogbonnia, K. J. Oyeniran, and P. I. Awopetu, "Effect of Raphia hookeri seed extract on blood glucose, glycosylated haemoglobin and lipid profile of alloxan induced diabetic rats," British Journal of Medicine and Medical Research, vol. 2, no. 4, pp. 621-635, 2012.

[47] E. C. C. Udenze, V. B. Braide, C. N. Okwesiliez, and G. C. Akuodor, "Pharmacological effects of Garcinia kola seed powder on blood sugar, lipid profile and atherogenic index of alloxan-induced diabetes in rats," Pharmacologia, vol. 3, no. 12, pp. 693-699, 2012.

[48] A. Atessahin, I. Karahan, G. Turk, S. Gur, S. Yilmaz, and A. O. Ceribasi, "Protective role of lycopene on cisplatin-induced changes in sperm characteristics, testicular damage and oxidative stress in rats," Reproductive Toxicology, vol. 21, no. 1, pp. 42-47, 2006.

[49] S. B. Mada, M. M. Abarshi, A. Garba et al., "Hypolipidemic effect of $\mathrm{N}$-acetylcysteine against dexamethasone-induced hyperlipidemia in rats," Calabar Journal of Health Sciences, vol. 3, no. 2, pp. 59-67, 2020.

[50] H. Akpan, P. Shallie, A. Adefule, and T. Adenowo, "Lipid peroxidation is key to neuronal cell death in the inferior colliculus of STZ-induced diabetic rats," Journal of Applied Life Sciences International, vol. 10, no. 1, pp. 1-15, 2017. 